\title{
Plazma Ark Kaynağıyla Birleştirilen AISI 410S Ferritik Paslanmaz Çeliğin Mikroyapı ve Mekanik Özelliklerine Isıl İşlemin Etkisi
}

Ceyhun $\mathrm{Köse}^{1 *}$, Ceyhun Topal ${ }^{2}$

1 Tokat Gaziosmanpaşa Üniversitesi, Mühendislik ve Mimarlık Fakültesi, Makine Mühendisliği Bölümü, Tokat, and Türkiye (ORCID: 0000-0002-3907-2226)

2 Tokat Gaziosmanpaşa Üniversitesi, Fen Bilimleri Enstitüsü, Mekatronik Mühendisliği Bölümü, Tokat, and Türkiye (ORCID: 0000-0001-8820-9316)

(İlk Geliş Tarihi 10 Nisan 2020 ve Kabul Tarihi 23 Mayıs 2020)

(DOI: $10.31590 /$ ejosat.717786)

ATIF/REFERENCE: Köse, C. \& Topal, C. (2020). Plazma Ark Kaynağıyla Birleştirilen AISI 410S Ferritik Paslanmaz Çeliğin Mikroyapı ve Mekanik Özelliklerine Isıl İşlemin Etkisi. Avrupa Bilim ve Teknoloji Dergisi, (19), 201-212.

$\ddot{\mathbf{O} z}$

Bu çalı̧̧mada, AISI 410S ferritik paslanmaz çelik saclar farklı kaynak parametreleri kullanılarak plazma ark kaynak yöntemi ile birleştirilmiştir. Plazma ark kaynaklı birleştirmelere kaynak sonrası 1 șıl işlem uygulanmıştır. Isıl işlemli ve 1sıll işlemsiz birleştirmelerin mekanik özellikleri ve mikroyapısı incelenmiştir. Çalışma sonucunda, artan 1sı girdisine bağlı olarak tane yapısının irileşmesi nedeniyle kaynaklı birleştirmelerin çekme dayanımı ve sertliğinde azalma meydana gelmiştir. Ayrıca 1sıl işlem uygulanan kaynaklı birleştirmelerin sertlik ve çekme dayanımı ısıl işlemsiz birleştirmelere göre daha düşük bulunurken, sünekliğin arttığı belirlenmiş̧ir.

Anahtar Kelimeler: Plazma ark kaynağı, Ferritik paslanmaz çelik, Mikroyapı, Mekanik özellikler, Isıl işlem.

\section{Influence of Heat Treatment on Microstructure and Mechanical Properties of Plasma Arc Welded AISI 410S Ferritic Stainless Steel}

\begin{abstract}
In this study, AISI $410 \mathrm{~S}$ ferritic stainless steel sheets were joined with plasma arc welding method by using different welding parameters. Heat treatment was applied to plasma welded joints. This study investigated mechanical properties and microstructure of heat treated and non heat treated plasma welded joints. The study revealed that, there have been decreases in tensile strength and hardness of welded joints because of grain coarsening caused by increasing heat input. Hardness and tensile strength of heat treated welded joints were lower and ductility was increasing compared to the ones of non heat treated welded joints.
\end{abstract}

Keywords: Plasma arc welding, Ferritic stainless steel, Microstructure, Mechanical properties, Heat treatment.

\footnotetext{
* Sorumlu Yazar: Tokat Gaziosmanpaşa Üniversitesi, Mühendislik ve Mimarlık Fakültesi, Makine Mühendisliği Bölümü,Tokat, Türkiye (ORCID: 0000-0002-3907-2226), ceyhun.kose@gop.edu.tr
} 


\section{Giriş}

Ferritik paslanmaz çeliklerin mikroyapıları baskın bir şekilde ferrit fazından oluştuğu için paslanmaz çelik grupları içerisinde bu çelikler ferritik paslanmaz çelik olarak adlandırılmaktadırlar [1] Ferritik paslanmaz çeliklerin, gerilmeli korozyon çatlağı, aralık korozyon ve çukurcuk korozyon dirençleri oldukça iyidir. Nikelsiz türlerinin östenitik paslanmaz çeliklere kıyasla fiyatı uygundur ve bu çeliklere iyi bir alternatif malzeme grubudur [1-4]. Mekanik özelliklerinden (dayanım, tokluk ve süneklik) ziyade iyi korozyon özellikleri nedeniyle pek çok endüstride kullanım alanı bulmaktadır. Düşük kromlu (\%10,5-12,5 Cr) ferritik paslanmaz çelikler özellikle otomotiv egzoz sistemlerinde yaygın olarak kullanılmaktadır. Ferritik paslanmaz çeliklerin ITAB (Isı Tesiri Altındaki Bölge) ve kaynak metalinde temel tane yapısı olarak ferrit fazının yanında, bazı koşullarda martenzit, karbür ve nitrür gibi ikincil faz oluşumlar da meydana gelebilmektedir [1,4]. Ferritik paslanmaz çeliklerin kaynağında ITAB, kaynak metalinde ergiyik metalin katılaşması sürecinde doğrudan ferrit oluşması ve bunun yanında tane irileşmesinin yaşanması bu çeliklerin kullanım alanlarını kısıtlamaktadır [1,2]. Ferritik paslanmaz çeliklerin ince taneli bir kaynak mikroyapısından oluşabilmesi için düşük 1sı girdisi elde edilebilen kaynak teknikleri önerilmektedir [1,4]. Ergitmeli kaynak teknikleri arasında düşük 1sı girdisine bağlı hızlı katılaşma oluşturan lazer kaynağı, TIG (Tungten Inert Gas) kaynağı, Lazer-TIG hibrit kaynağı ve plazma transfer ark kaynak yöntemleri sayilabilmektedir [4,5].

Geleneksel ark kaynak teknikleriyle kıyaslandığında yüksek enerji yoğunluğu ve çabuk katılaşma meydana getirmesi sebebiyle plazma ark kaynağı ile birleştirilen ferritik paslanmaz çeliklerin ergime bölgesinde tane irileşmesi önlenebilir [4]. Plazma ark kaynağı, çok yüksek bir sıcaklığa 1sıtılarak iyonize olmuş ve elektrik iletkenliği kazanmış plazma gazı sayesinde, elektrik arkının tungsten elektrodun ucundan malzemeye transfer edildiği ve böylelikle arkın oluşturulduğu bir kaynak tekniğidir [4]. Arkın oluşturduğu isı enerjisi malzemeyi eritmektedir. Plazma ark kaynă̆ı, düşük 1sı girdisi ve yüksek soğuma oranına sahiptir. Ayrıca yüksek yoğunlaşma enerjisi, yüksek kaynak hızı, dar kaynak bölgesi, derin nüfuziyet, otomasyona uygunluk, yüksek mekanik dayanım, düşük distorsiyon ve ilave tel kullanmadan kaynak yapabilme imkanı sağlamaktadır [3-10].

Ferritik paslanmaz çeliklerin kaynağında karşılaşılan diğer sorun da ITAB ve kaynak metalinde oluşum gösteren sigma fazıdır. Sigma fazı tokluk ve süneklikte azalmaya sebebiyet vermektedir [1,4,11]. Kaynaklı birleştirmelerin mekanik özelliklerini iyileştirme tekniklerinden birisi kaynak sonrası 1sıl işlemler olarak gösterilmektedir [1,4]. Ferritik paslanmaz çelik birleştirmelere gerçekleştirilen 1sıl işlemler ile tokluğun, sünekliğin ve korozyon dayanımlarının arttığı vurgulanmaktadır [1]. Kaynak sonrası 1sıl işlemin $750-800^{\circ} \mathrm{C}$ sıcaklık aralığında gerçekleştirilmesi kalıntı gerilmeleri azaltmakla birlikte mikroyapıyı önemli derece etkilememekte yalnızca martenzit temperlenmektedir [1,12]. Ayrıca bu ısıl işlem sıcaklık aralığı östenitin yeniden oluşması için gerekli olan sıcaklığın altında bir sıcaklıktır [1,13]. Fakat bu sıcaklıkta tutma süresi arttıkça bazı mikroyapısal dönüşümlerin oluşabileceği gözardı edilmemelidir. Ferritik paslanmaz çeliklerin kaynağında bazı sorunlarla karşılaşılabilmektedir. Kaynak işlemi sırasında özellikle ITAB'da oluşum gösteren ve toklukta önemli bir azalmaya sebep olan tane irileşmesi ve gevrek çatlak sorunu en önemli problemlerdendir.

$\mathrm{Bu}$ çalışmada, plazma kaynak prosesi iki farklı kaynak gücü ve sabit kaynak hızıyla gerçekleştirilerek ısı girdisi şartlarının ferritik paslanmaz çelik birleştirmelerin mekanik ve mikroyapı özelliklerine etkisi incelenmiştir. Ayrıca birleştirmelere kaynak sonrası 1sıl işlem uygulanmış ve 1 sıl işlemin mekanik özelliklere ve mikroyapıya etkisi araştırılmıştır.

\section{Materyal ve Metot}

\subsection{Malzeme ve Kaynak İşlemi}

Bu çalışmada, AISI 410S ferritik paslanmaz çelik sac levhalar deneylerde kullanılmıştır. Bu levhalar 90×180×0.6 mm ebatlarında lazer kesim tezgahında kesilmiştir. AISI 410S ferritik paslanmaz çeliğin kimyasal kompozisyonu spektral analiz ile belirlenmiş ve Tablo 1'de verilmiştir.

Tablo 1. AISI 410 ferritik paslanmaz çeliğin kimyasal kompozisyonu (\% ă̆ırlık).

\begin{tabular}{l|l|l|l|l|l|l|l|l}
\hline$\% \mathrm{C}$ & $\mathrm{Si}$ & $\mathrm{Mn}$ & $\mathrm{P}$ & $\mathrm{S}$ & $\mathrm{Ni}$ & $\mathrm{Ti}$ & $\mathrm{Cr}$ & $\mathrm{Fe}$ \\
\hline 0,047 & 0,374 & 0,414 & 0,020 & 0,015 & $<0,0001$ & 0,060 & 14,065 & Kalan \\
\hline
\end{tabular}

Ferritik paslanmaz çelik levhalar Tablo 2'de verilen parametreler kullanılarak, 50 A akıma sahip EWM marka Inverter Microplasma 50 plazma ark kaynak makinesi yardımıyla, yatay pozisyonda ve ilave metal kullanılmadan birleştirilmiştir (Şekil 1). Kaynak sonrası plazma kaynaklı numunelere firında $770{ }^{\circ} \mathrm{C}$ 'de 60 dakika 1 sıl işlem yapılmıştır ve numuneler firından çıkarılarak soğumaya bırakılmıştır.

Tablo 2. Plazma ark kaynak parametreleri.

\begin{tabular}{c|c|c|c|c|c}
\hline Numune & $\begin{array}{c}\text { Plazma ark gücü } \\
\text { (A) }\end{array}$ & $\begin{array}{c}\text { Kaynak hızı } \\
(\mathrm{mm} / \mathrm{s})\end{array}$ & Koruyucu gaz / plazma ve destek gazı & $\begin{array}{c}\text { Gaz debisi } \\
(\mathrm{lt} / \mathrm{dk})\end{array}$ & $\begin{array}{c}\text { Is1 girdisi } \\
(\mathrm{kJ} / \mathrm{mm})\end{array}$ \\
\hline B1 & 20 & 1 & Argohid-5 / Saf Argon & 20 & 0.48 \\
\hline B2 & 22 & 1 & Argohid-5 / Saf Argon & 20 & 0.52 \\
\hline
\end{tabular}




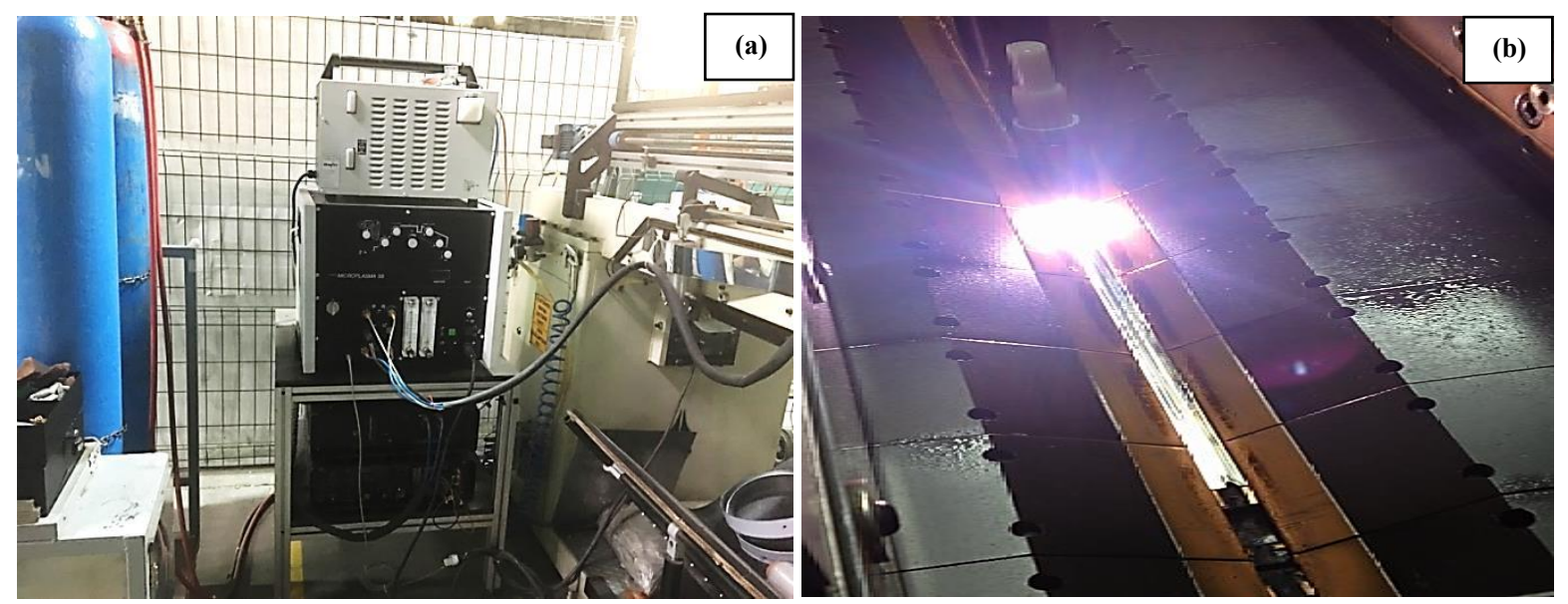

Şekil 1. (a) Plazma ark kaynak makinesi, (b) kaynak işlemi.

\subsection{Mikroyapı ve Mekanik Özellikler}

Lazer kesimle elde edilen deney numunelerinin mikroyapı incelemeleri için Kalling No.2 çözeltisinde 20 saniye süreyle dağlama uygulanmıştır. Mikroyapı incelemeleri NIKON marka optik mikroskop, JEOL JSM 6060 LV marka taramalı elektron mikroskobu (SEM) ve Enerji Dağılım Spektrometresi (EDS) donanımıyla gerçekleştirilmiştir. Makroyapı incelemeleri ise NIKON SMZ25 marka optik stereoskop ile belirlenmiştir. X-Işııı Difraksiyonu (XRD) analizi RIGAKU Smart Lab cihazı ile elde edilmiştir. Çekme testi için her bir parametreden üçer adet numune hazırlanmış ve çekme testi INSTRON marka çekme testi cihazıyla $10 \mathrm{~mm} / \mathrm{dk}$. çekme hızında gerçekleştirilmiştir. Kaynaklı birleştirmelerin ana malzeme, ITAB ve kaynak metali sertlik ölçümü ise, WILSON Hardness 402MVD marka Vickers sertlik ölçüm cihazı ile belirlenmiştir.

\section{Araştırma Sonuçları ve Tartışma}

\subsection{Makroyapı İncelemeleri}

Plazma kaynağı yüksek enerji yoğunluğu ve düşük 1sı girdisine sahip bir proses olması nedeniyle, kaynak dikişlerinde katılaşma çok hızlı bir şekilde gerçekleşmekte ve yüksek nüfuziyet/genişlik oranları meydana gelmektedir. Kaynak havuzundaki 1sı ve sıvı akışı, sıcaklık değişimleriyle önemli oranda etkilenmekte ve kaynak havuzundaki sıvı akışı ve taşınımlı 1sı transferi sonucunda ergime bölgesinin son şekli ve nüfuziyet oranı elde edilmektedir [4]. Farklı kaynak gücüne bağlı olarak değişiklik gösteren kaynak dikiş boyutları Şekil 2'de gösterilmiştir. Artan plazma kaynak gücüne bağlı olarak artan 1sı girdisinden dolayı kaynak dikişinin genişlediği gözlenmiştir.
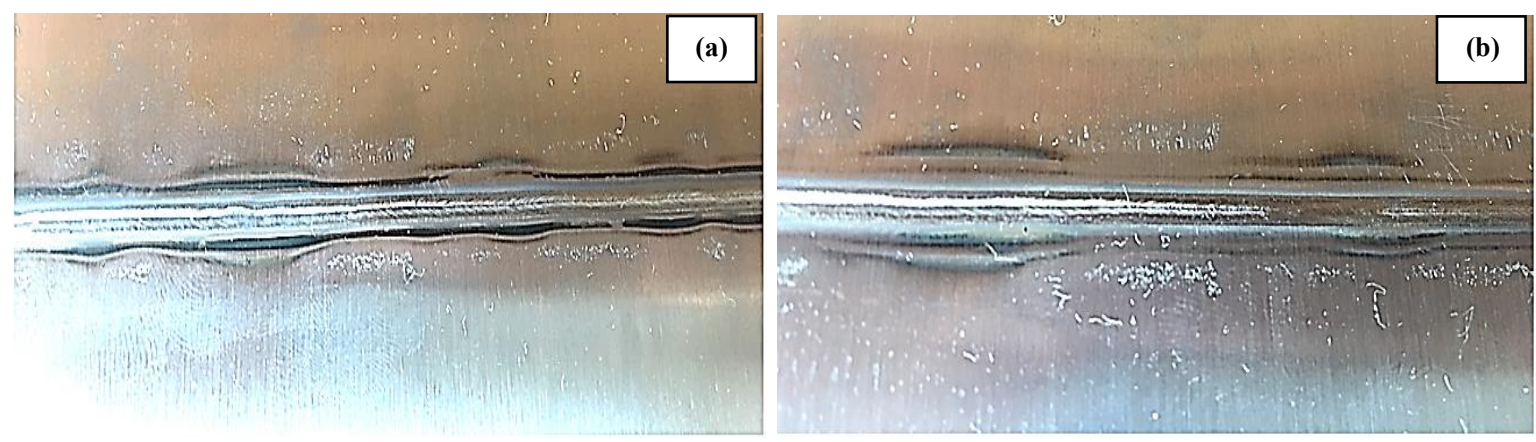


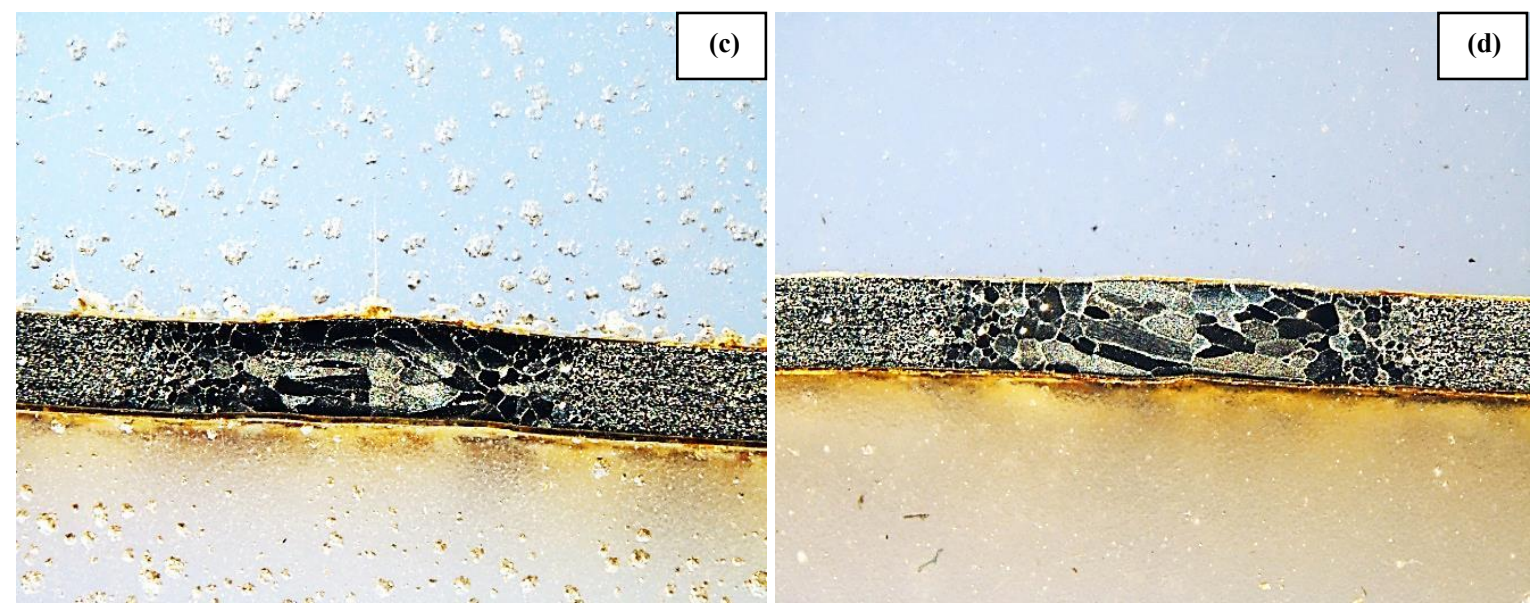

Şekil 2. B1 ve B2 numunelerinin makro görüntüsü ve kaynak dikiş profili, (a) B1 numunesinin makro görüntüsü, (b) B2 numunesinin makro görüntüsü, (c) B1 numunesinin kaynak dikiş profili, (d) B2 numunesinin kaynak dikiş profili.

\subsection{Mikroyapı İncelemeleri}

Ana malzeme mikroyapı görüntüleri incelendiğinde baskın bir şekilde eş eksenli ferrit tanelerinden meydana geldiği gözlenmektedir (Şekil 3).
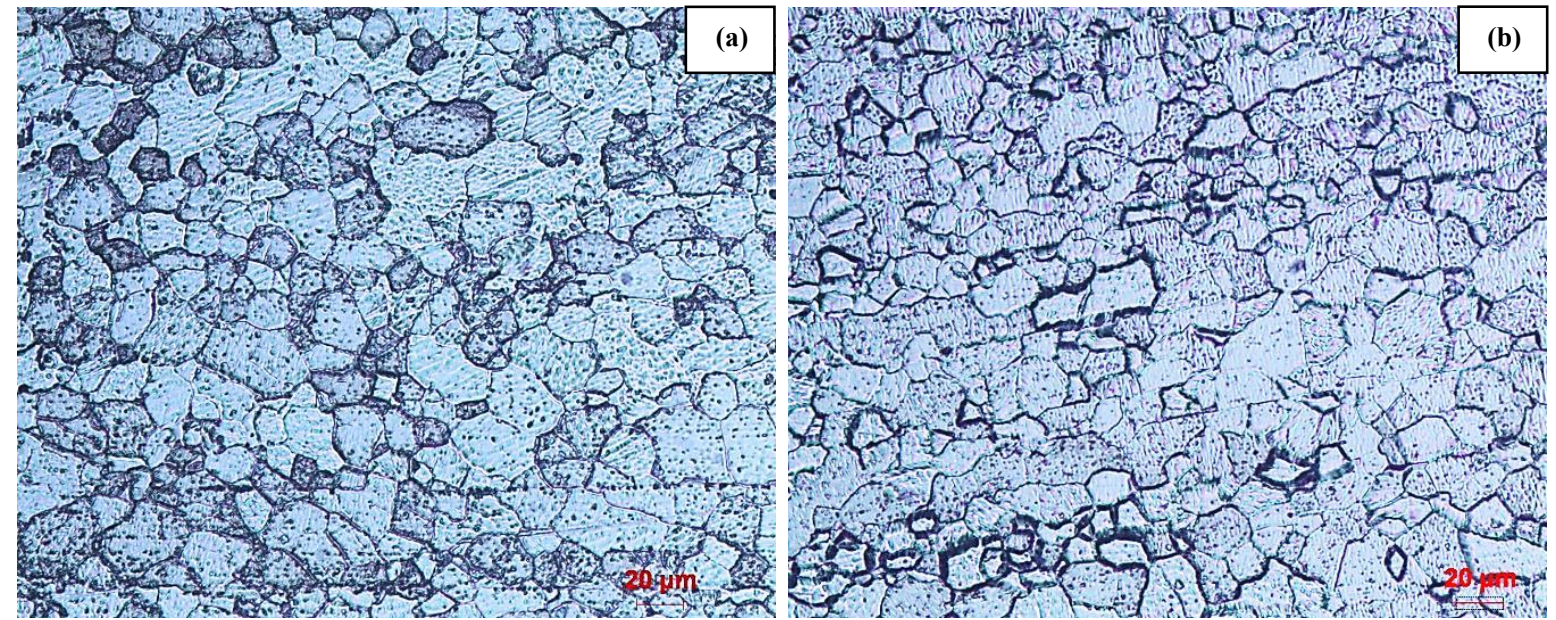

Şekil 3. AISI 410S ferritik paslanmaz çeliğin mikroyapısı; (a) ısıl işlemsiz, (b) ısıl işlemli ana malzeme görüntüsü.

Farklı 1Sı girdisi ile birleştirilen numunelerin ITAB'ında belirgin olarak tane büyümesinin gerçekleştiği ve tane büyüklüğünün kaynak metali tane yapısından daha iri olduğu görülmektedir (Şekil 4). Kaynak metalinin ise kısmen sütunsal ve eşeksenli ferrit tanelerinden oluştuğu gözlenmiştir. Ferritik paslanmaz çeliğin kaynak mikroyapısı çoğunlukla birincil ferrit şeklinde oluşmaktadır [1]. Kaynak metalinin tamamı ferrit veya ferrit ve martenzit tanelerinden oluşmaktadır. Martenzit, ferrit tane sınırlarında tane sınırı martenziti şeklinde yerleşmektedir [1,14]. Düşük kaynak gücü yani düşük 1s1 girdisiyle birleştirilen B1 numunesinin $(0,48 \mathrm{~kJ} / \mathrm{mm})$ mikroyapıs1 yüksek 1S1 girdisiyle birleştirilen B2 numunesinin $(0,52 \mathrm{~kJ} / \mathrm{mm})$ mikroyapısına göre daha küçük ferrit tanelerinden meydana gelmiştir (Şekil 4). B1 numunesinin kaynak bölgesinde hızlı soğuma gerçekleşmesi sebebiyle ince taneli bir mikroyapı elde edilmiştir. Kaynak termal döngüsünün ilk safhalarında, ikili faz $(\alpha+\gamma)$ soğutulduklarında ITAB'da östenit çekirdeklenmesinin engellenebildiği ve tamamen ferritik mikroyapı modu elde edilebileceği ifade edilmektedir [4].

B1 numunesinin ITAB'ında ana malzemeye kıyasla küçük bir oranda tane büyümesinin oluştuğu, bu tane büyümesinin sınırlı olduğu, kaynak metalinin ise ITAB'a göre daha homojen ve ince ferrit tanesinden meydana gelmiştir. Ayrıca, tane sınırlarında küçük oranlara sahip martenzit gözlenmiştir. B2 numunesinin mikroyapısı incelendiğinde ise düşük katılaşma oranına bağlı olarak, ITAB'ın daha iri tanelerden oluştuğu, kaynak metalinin ise sütunsal bir tane morfolojisinden meydana geldiği görülmüştür. İri tane yapısından meydana gelen kaynaklı birleştirmelerde zayıf mekanik özellikler elde edilmektedir. Isı girdilerindeki farklılık sebebiyle, özellikle de yüksek 1sı girdisiyle birleştirilen numunede sütunsal ferrit ve tane sınırı martenzitin hacim oranları değişmiş ve hacimlerinin belirgin olarak artmıştır. Ferritik paslanmaz çeliğin kaynak metalinin katılaşma hızı önemli bir yer tutmaktadır. Hızlı katılaşma durumunda martenzit tane yapısı meydana gelmektedir [15]. Ferritik paslanmaz çeliklerin kaynaklı birleştirmelerinde artan 1sı girdisine, artan 1sıl işlem sıcaklığına ve bu yüksek sıcaklıkta uzun süre bekleme şartlarında \%100 ferritik bir mikroyapı oluşmaz ise küçük hacimli östenit oluşabilir. Küçük hacimli östenit de, 1sı girdisine bağlı olarak değişen katılaşma oranı sonucunda martenzite dönüşeceği araştırmacılar 
tarafından vurgulanmaktadır [16]. Eğer martenzit dönüşümü gerçekleşmez 1sı girdisinin etkisiyle aşırı tane irileşmesi meydana gelirse, mekanik özelliklerin azalacağı araştırmacılar tarafından özellikle rapor edilmiștir [16]. Kaynak metali ve ITAB'da herhangi bir gözenek, süreksizlik veya çökelti oluşumları gözlenmemiştir. İkincil faz oluşumlarının tokluk ve süneklik değerlerinde azalışa sebep olacağ
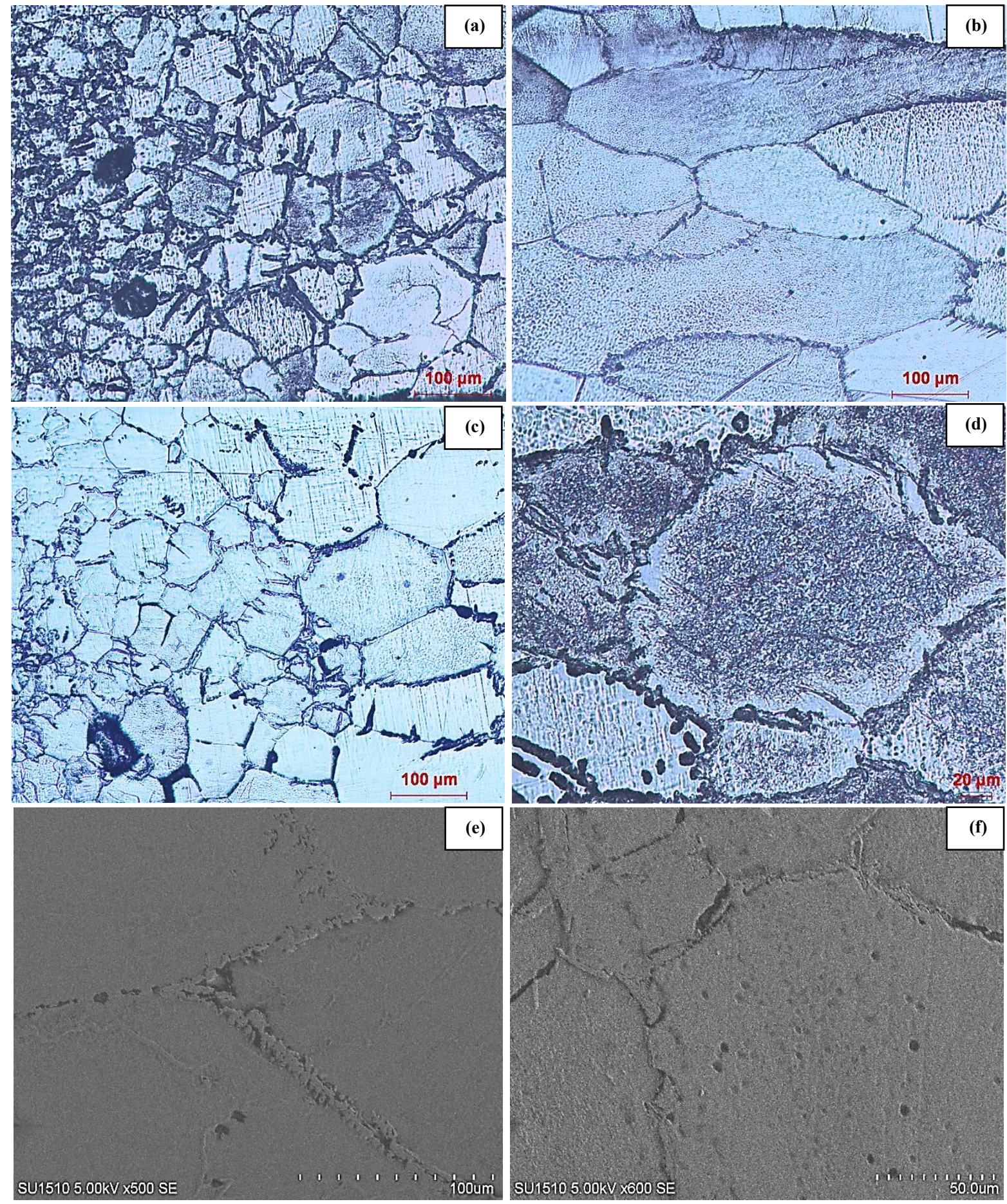

Şekil 4. (a), (b) B1 numunesinin ITAB ve kaynak metali optik mikroskop görüntüsü, (c), (d) B2 numunesinin ITAB ve kaynak metali optik mikroskop görüntüsü, (e), (f) B1 ve B2 numunelerinin kaynak metali SEM görüntüsü.

Isıl işlem uygulanan kaynaklı birleştirmelerin (1S1 işlemli numuneler H harfi ile kodlanmıştır) optik mikroskop ve SEM görüntüleri Şekil 5'de verilmiştir. Yüksek 1sı girdisi $(\mathrm{B} 2 \mathrm{H})$ ve düşük 1sı girdisiyle birleştirilen numunelerin $(\mathrm{B} 1 \mathrm{H})$ mikroyapıları incelendiğinde, B2H numunesinin ITAB'1nda artan 1s1 girdisine, 1sıl işlem sürecine ve bu sıcaklıkta tutmanın etkisiyle sütunsal tane irileşmesi görülmüştür (Şekil 5c). B2H numunesinde, 1S1 girdisi etkisinin yanında 1sıl işlemin etkisiyle de kaynak metalinde sütunsal ve iri yapılı ferrit tanelerinin oluştuğu ve tane sınırlarında martenzit meydana geldiği gözlenmiştir (Şekil 5d). Ayrıca birleştirmelerde krom karbür gibi yapıların meydana gelmediği mikroyapı görüntülerinden anlaşılmaktadır. Bu sonuçlardan anlaşılacağı üzere, ısıl işlemli numunelerin mikroyapılarında ısıl işlemsiz numunelere kıyasla belirgin olarak tane büyümesi oluşmuştur. 

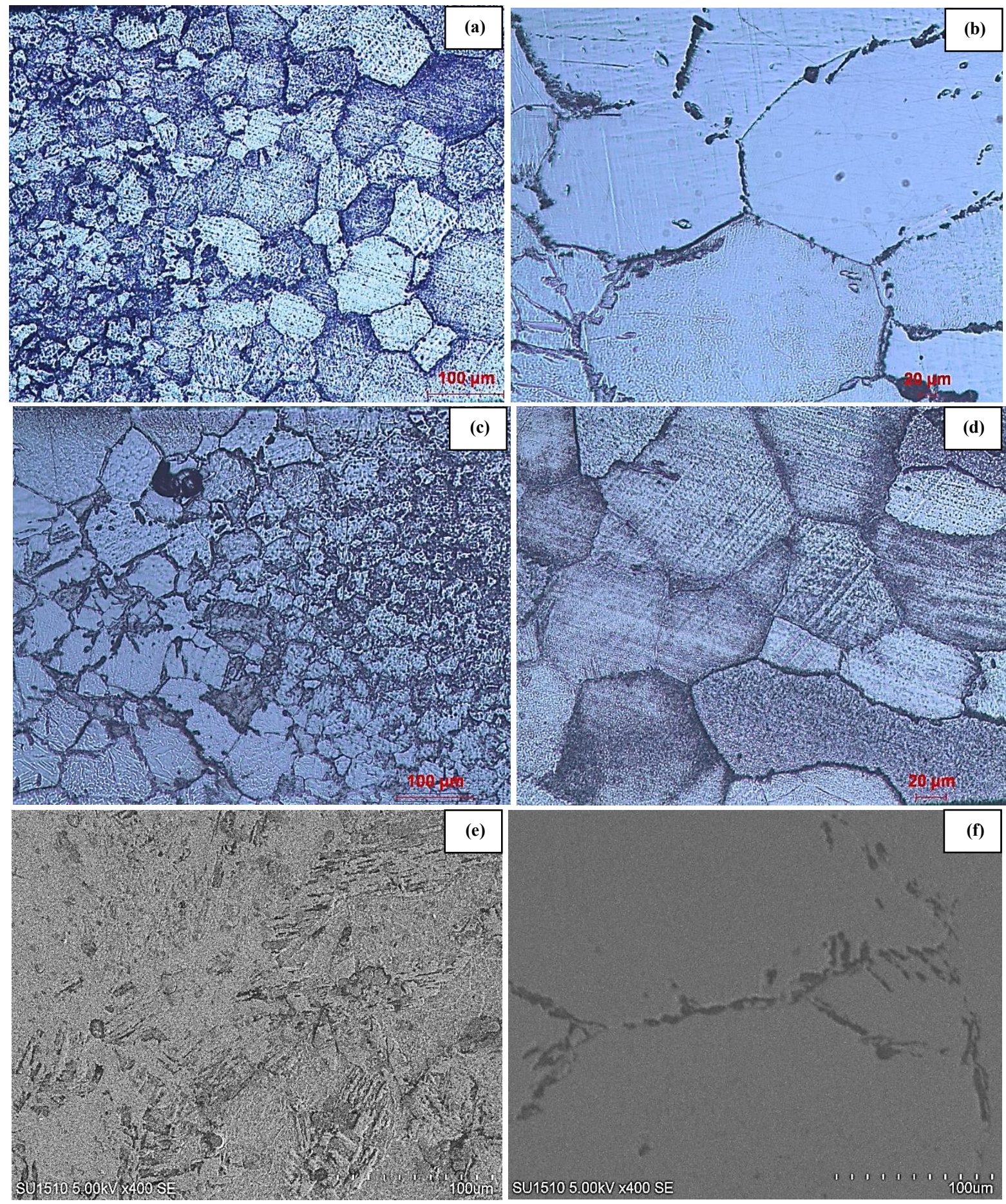

Şekil 5. (a), (b) B1H numunesinin ITAB ve kaynak metali optik mikroskop görüntüsü, (c), (d) B2H numunesinin ITAB ve kaynak metali optik mikroskop görüntüsü, (e), (f) B1H ve B2H numunelerinin kaynak metali SEM görüntüsü.

Yüksek 1sı girdisiyle birleştirilen ve ısıl işlemli B2H numunesinin kaynak metali EDS analiz sonucu incelendiğinde (Şekil 6.), Tablo 1'de verilen spektral analiz sonucuyla uyumlu olduğu tespit edilmiştir. Plazma ark kaynağı ve 1 sıl işlem nedeniyle belirgin bir alaşım elementi kaybının oluşmadığı belirlenmiştir. 


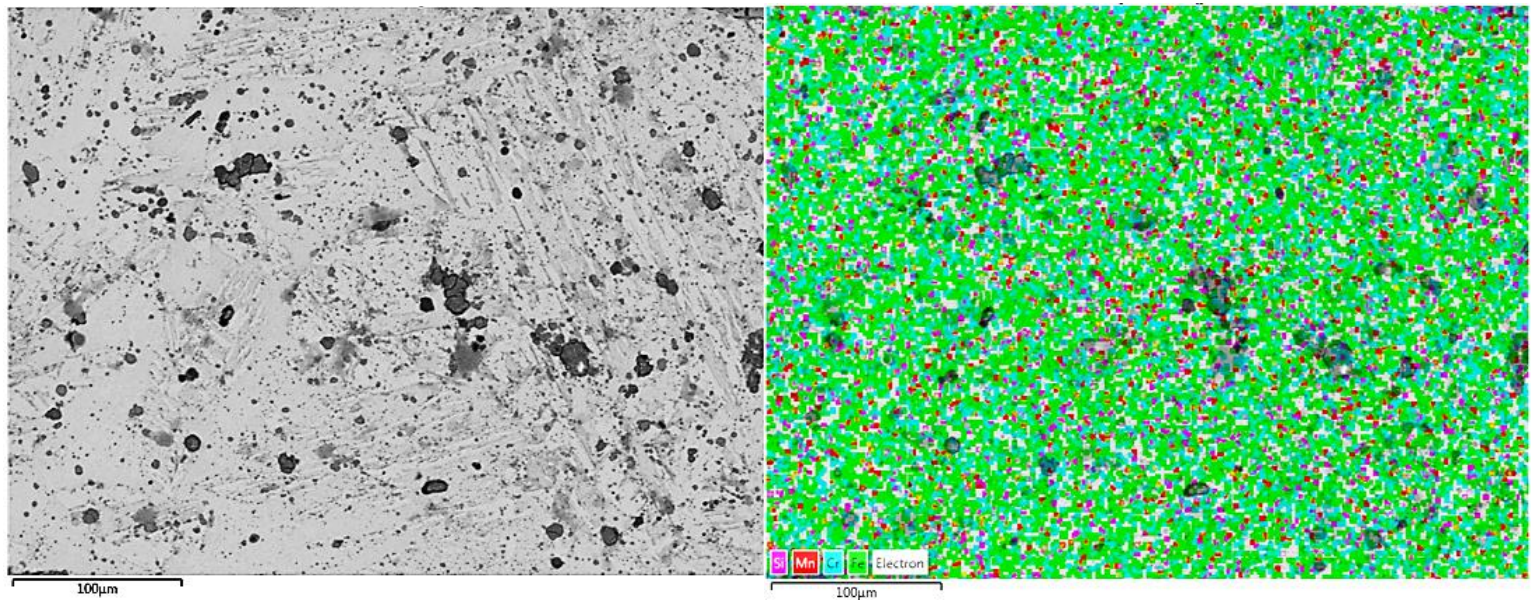

Fe $K \alpha 1$

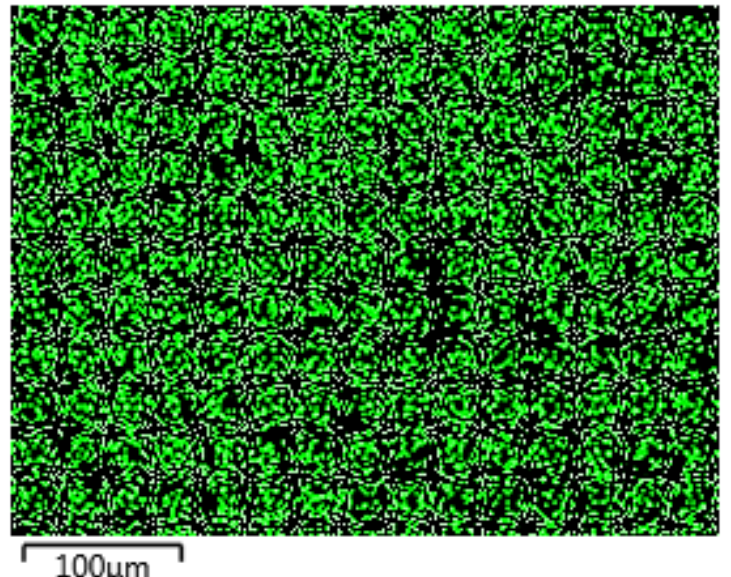

$100 \mu \mathrm{m}$

Si K 11

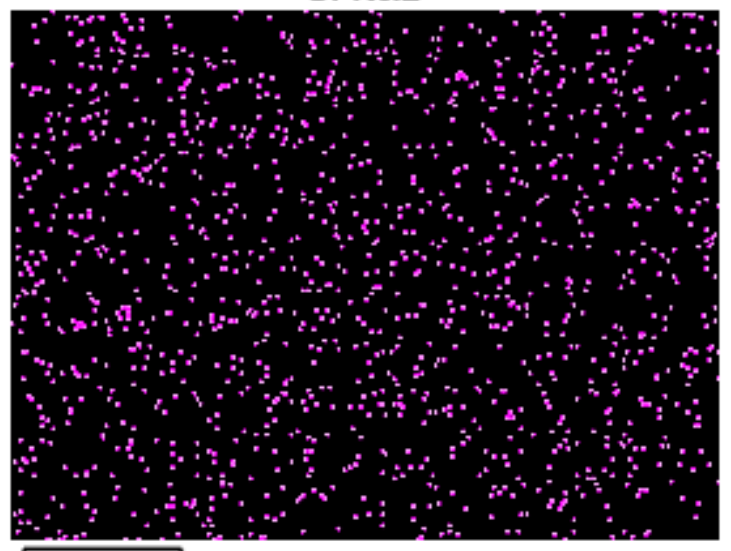

$100 \mu \mathrm{m}$

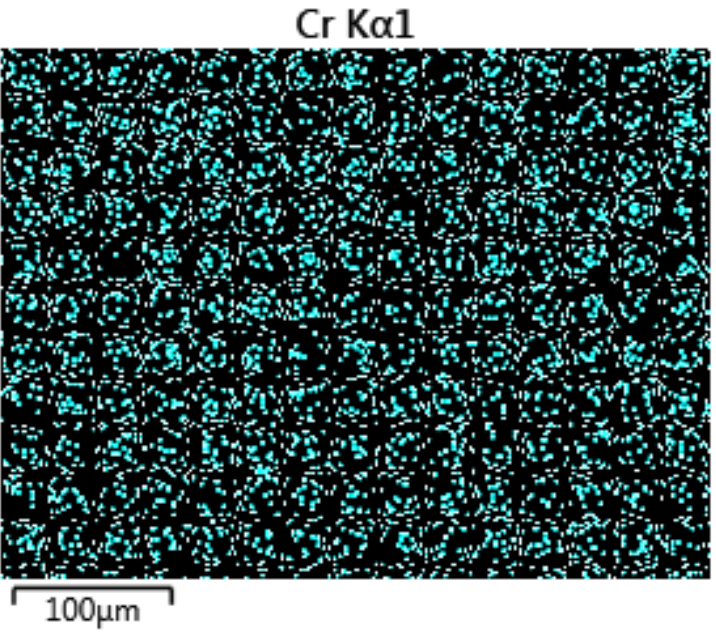

Mn K $\alpha 1$

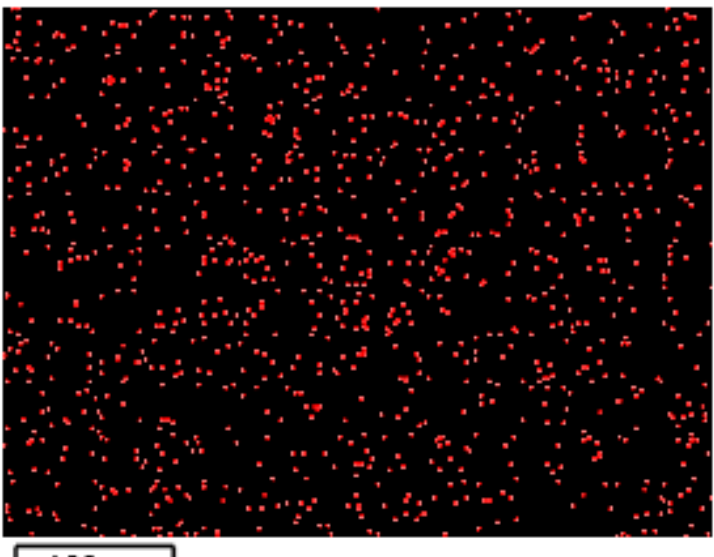

$100 \mu \mathrm{m}$

Sekil 6. B2H numunesinin kaynak metali bölgesinin SEM-EDS analizi sonuçları.

XRD analizlerinden, AISI 410S ferritik paslanmaz çelik ana malzeme ve kaynaklı birleştirmelerde ferrit $(\alpha)$, ve martenzit $\left(\alpha^{\mathrm{I}}\right)$ fazlarının dişında herhangi bir faz oluşumu tespit edilmemiştir (Şekil 7). Ana malzemeye ait pikler ile kaynaklı birleştirmelerin pikleri karşılaştırıldığında, kaynaklı numune piklerinde keskinlik ve sıklığın yoğun olduğu ve pik şiddetlerinde belirgin artışlar olduğu görülmüştür. Ayrıca, SEM-EDS analizleri ile tespit edilemeyen krom karbür, nitrür gibi oluşumlar, XRD vasıtasıyla da belirlenememiştir. 


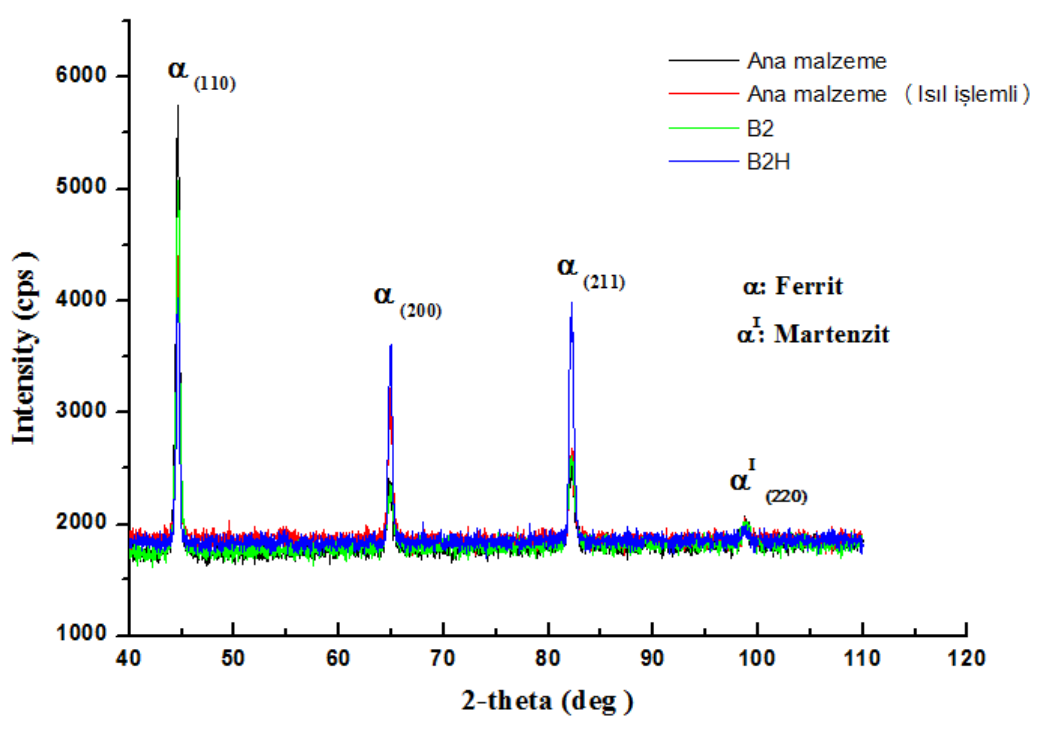

Şekil 7. XRD analizi.

\subsection{Mekanik Özelliklerin İncelenmesi}

\subsection{1. Çekme deneyi}

Ana malzeme ve plazma kaynaklı birleştirmelerin mekanik özelliklerini belirlemek için çekme testi uygulanmış, sonuçlar sırasıyla gerilme-birim şekil değiştirme grafikleri olarak Şekil 8'de ve Tablo 3'te verilmiştir. B2 ve B2H numunelerinin çekme deneyi sonrası görüntüleri de Şekil 9'da gösterilmiştir.

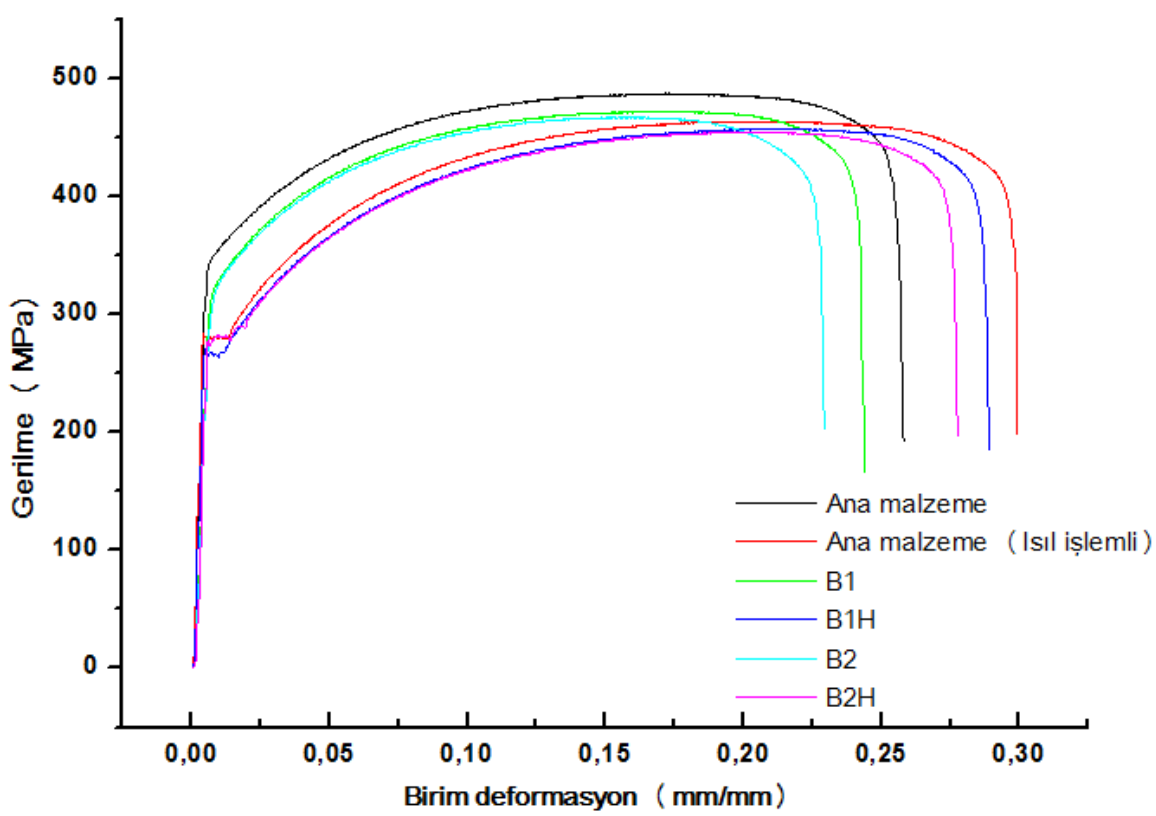

Şekil 8. Gerilme-birim şekil değiştirme diyagramı.

Tablo 3. Çekme deneyi sonuçlart.

\begin{tabular}{c|c|c|c}
\hline Numune & $\begin{array}{c}\text { Çekme dayanımı } \\
(\mathbf{M P a})\end{array}$ & $\begin{array}{c}\text { Akma dayanımı } \\
(\mathbf{M P a})\end{array}$ & $\begin{array}{c}\text { Uzama } \\
(\mathbf{\%})\end{array}$ \\
\hline Ana malzeme & 490 & 349 & 26.5 \\
\hline Ana malzeme (1s1l işlemli) & 463 & 290 & 30 \\
\hline B1 & 470 & 328 & 24.8 \\
\hline B1H & 455 & 257 & 29 \\
\hline B2 & 465 & 322 & 22.6 \\
\hline B2H & 452 & 254 & 27.6 \\
\hline
\end{tabular}




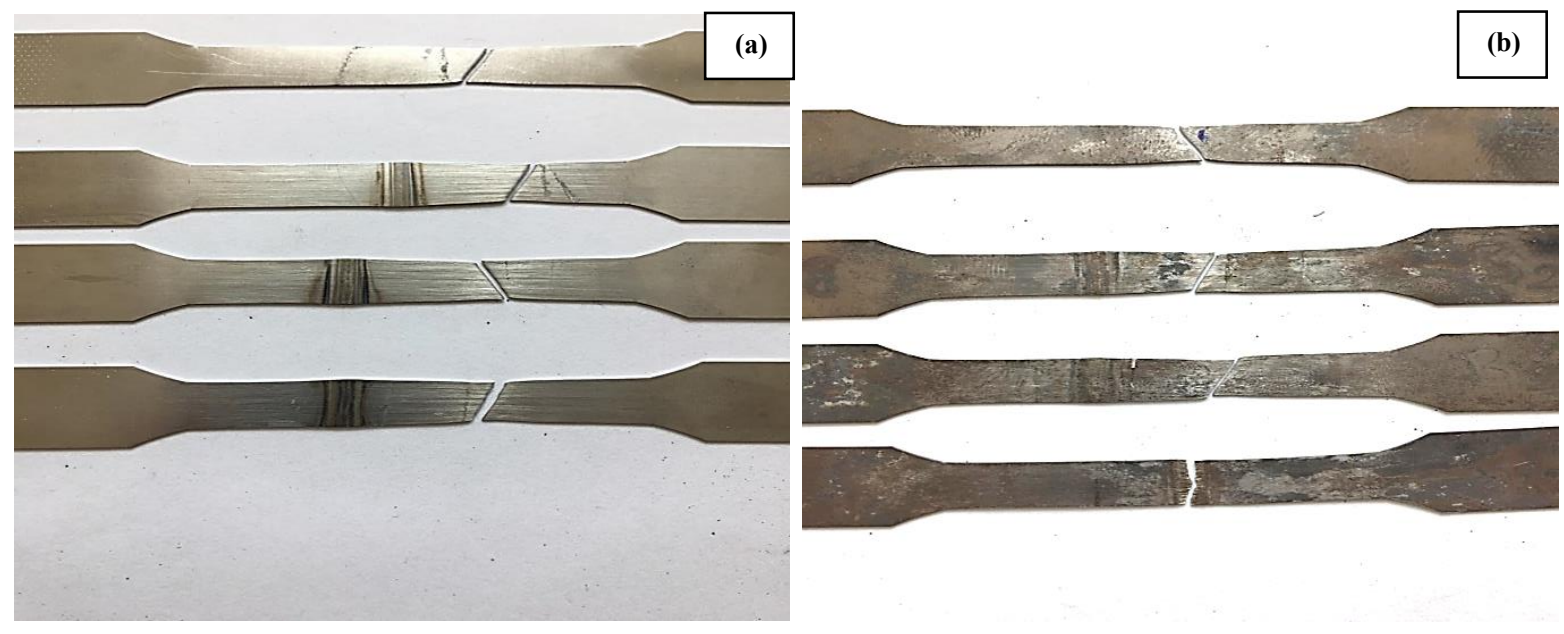

Şekil 9. (a) B2, (b) B2H numunelerinin çekme deneyi sonrası görüntüleri.

Isıl işlem uygulanan birleştirmelerin çekme deneyi sonuçları incelendiğinde (Şekil 8 ve Tablo 3), ana malzemenin çekme dayanımı, akma dayanımı ve sünekliğinin kaynaklı birleştirmelerden daha yüksek olduğu görülmüştür. Kaynaklı numunelerin mekanik özelliklerinin ana malzemeye göre düşük çıkmasının başlıca sebebinin, kaynak esnasında kaynak dikişinde oluşum gösteren morfolojik dönüşümlerdir. Kaynak bölgesine gönderilen 1sı girdisinin etkisiyle, mikroyapıda meydana gelen irileşmeler çekme ve akma dayanımındaki azalmaya neden olarak düşünülmektedir. Ferritik paslanmaz çeliklerin mikroyapıları ergime noktasından oda sıcaklığına kadar özünde tamamen ferritik olacağı araştırmacılar tarafindan belirtilmektedir [1,17]. Sonuç olarak, mikroyapıda çok küçük hacim oranına sahip martenzit veya küçük orandaki östenitin martenzite dönüşümü, dayanım artışına esasen büyük bir etkisinin olmayacağı vurgulanmaktadır $[1,18,19]$. Özellikle karbon ve azotun varlığı sebebiyle, katı-eriyik sertleşmesiyle dayanımda belirli bir oranda artış oluşabileceği ifade edilmektedir $[1,18,19]$. Ancak, mikroyapıda meydana gelen martenzit hacmindeki artış ve küçük boyuttaki çökeltilerin mekanik özelliklerin artışına sebep olabileceği gözardı edilmemelidir. Çekme deneyi sonuçlarından, ana malzemenin ortalama çekme dayanımı 490MPa olarak tespit edilmiş̧ir. Düşük 1s1 girdisiyle birleştirilen B1 numunesinin $(0,48$ $\mathrm{kJ} / \mathrm{mm}$ ) ortalama çekme dayanımı $470 \mathrm{MPa}$ bulunurken, B2 numunesinin $(0,52 \mathrm{~kJ} / \mathrm{mm})$ ortalama çekme dayanımı $465 \mathrm{MPa}$ olarak tespit edilmiştir. Uzama değerlerine bakıldığında ise kaynaklı numunelerin sünekliğinin ana malzemeden daha düşük olduğu belirlenmiştir. Sonuçlardan ayrıca, farklı 1sı girdisiyle birleştirilen numunelerin çekme dayanımlarının birbirine yakın olduğu tespit edilmiştir. Kaynaklı birleştirme işleminin ilave metal kullanılmadan ana metalin ergitilmesiyle gerçekleştirilmesi ve 1sı girdileri arasındaki farkın çok büyük olmayışı bu sonucun alınmasına neden olduğu düşünülmektedir.

Isıl işlemli plazma kaynaklı numunelerin çekme dayanımı sonuçları incelendiğinde ise (Şekil 8 ve Tablo 3.), ana malzemenin çekme dayanımı, akma dayanımı değerleri, farklı ısı girdisiyle birleştirilen plazma ark kaynaklı numunelerden daha yüksek olduğu sonuçlardan anlaşılsa da kaynaklı birleştirmelerin dayanımlarının ana malzemenin dayanımına çok da uzak olmadıkları tespit edilmiştir. Ana malzemenin çekme dayanımı $463 \mathrm{MPa}$ olarak belirlenirken, yüksek 1sı girdisiyle birleştirilen B2H numunesinin $(0,52$ $\mathrm{kJ} / \mathrm{mm})$ çekme dayanımı $452 \mathrm{MPa}$ olarak, B1H numunesinin $(0,48 \mathrm{~kJ} / \mathrm{mm})$ çekme dayanımı $455 \mathrm{MPa}$ olarak bulunmuştur. Kaynak bölgesine iletilen 1sı girdisi ve kaynak sonrası uygulanan $1 s ı$ işlem sebebiyle, kaynak mikroyapısında meydana gelen dönüşümler ve tane irileşmeleriyle ana malzeme dayanımına kıyasla küçük düşüşler yaşandığı düşünülmektedir. Kaynak sonrası uygulanan ısıl işlem nedeniyle numunelerin süneklik değerlerinde önemli bir düşüş yaşanmadığı sonucuna ulaşılmıştır. Yüzde uzama değerlerinin ana malzemenin uzama değerine yakın olduğu tespit edilmiştir. Ayrıca 1 sıl işlem uygulanan numunelerin dayanımlarının 1 sıl işlem uygulanmayan numunelere kıyasla daha düşük olduğu anlaşılmıştır. Isıl işlem nedeniyle mikroyapının daha fazla yumuşaması ve morfolojik dönüşümlerin bu sonucun ana sebebi olduğu düşünülmektedir.

Isıl işlemsiz ve ısıl işlemli ana malzeme ve plazma kaynaklı numunelerin çekme deneyi sonrası kırılma yüzeylerine ait SEM görüntüleri incelendiğinde (Şekil 10), ana malzemede ve plazma kaynaklı numunelerde sünek kırılma biçimini ifade eden lokal çukurcuk yüzey morfolojisiyle birlikte kırılmanın gerçekleştiği gözlenmiştir. Birleştirmelerin kırılma yüzeyi görüntülerinde herhangi bir inklüzyon oluşumuna rastlanmamıştır. 

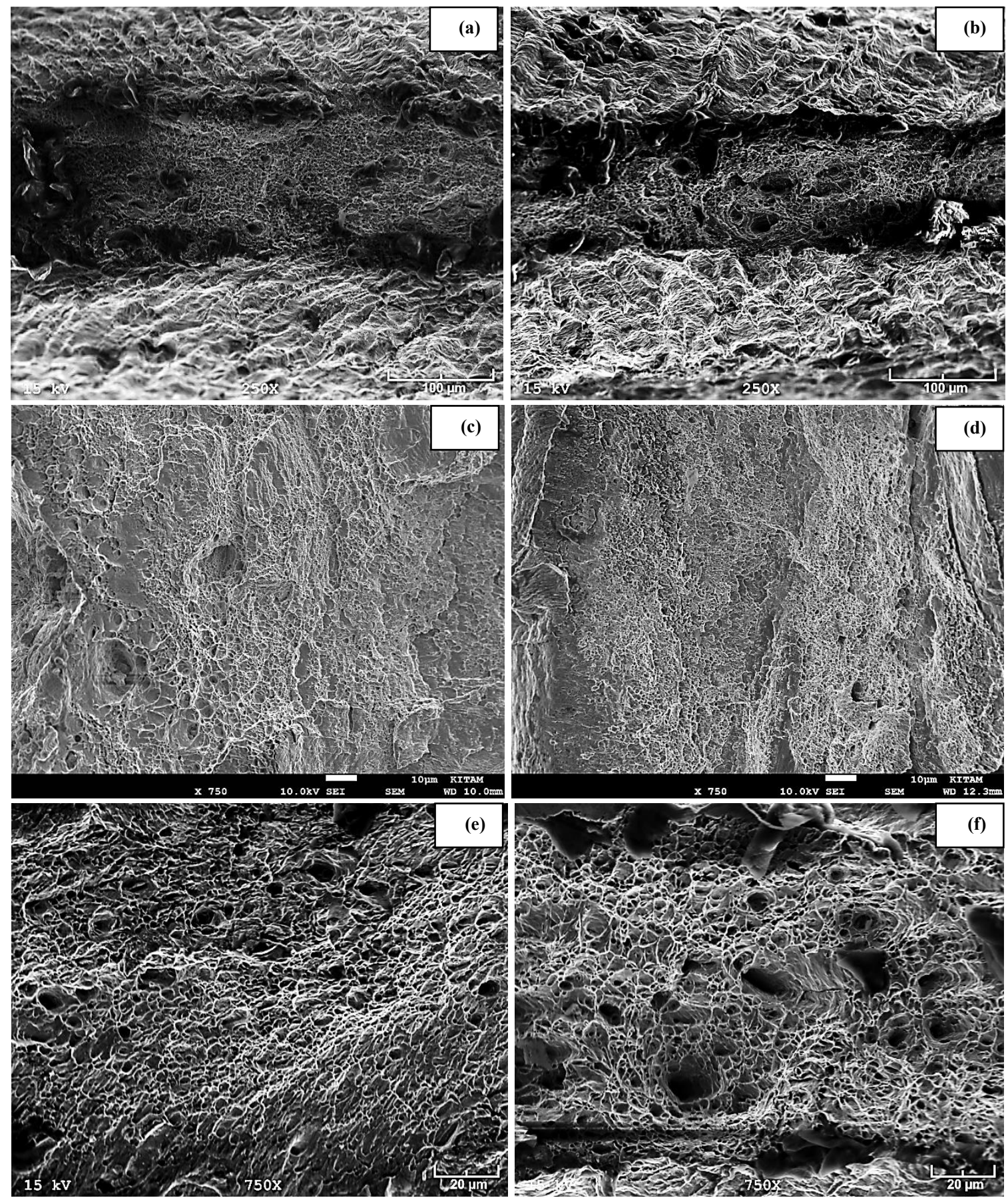

Şekil 10. Isıl işlemsiz ve isll işlemli ana malzemeler ve plazma kaynaklı numunelerin çekme deneyi sonrası kırılma yüzeyi SEM görüntüleri; (a) Ana malzeme (b) Ana malzeme (lsil işlemli), (c) B1, (d) B2, (e) B1H, (f) B2H.

\subsubsection{Mikrosertlik}

Plazma kaynağı geleneksel ergitmeli kaynak tekniklerine kıyasla düşük 1sı girdisi ve hızlı soğuma meydana getirmesi sebebiyle daha küçük tanelerden oluşan bir mikroyapı oluşturmakta ve böylece ITAB ve kaynak metalinde yüksek sertlikler elde edilmektedir. Birleștirmelerde sertlik dağılımı temelde mikroyapıyla ilişkilidir. Ferritik paslanmaz çeliklerde martenzit oluşumu sertliğin yükselişinde önemli bir yere sahiptir. Isı girdisi ise sertlik değişimlerinde en önemli faktördür. Ayrıca mikroyapıda oluşum gösteren nitrür veya karbürler de sertlik dağılımında etkili olmaktadır. B1 ve B2 numunelerinin sertlik dağılımlarına bakıldığında (Şekil 11), kaynak metali ve ITAB sertliğinin ana metalden daha yüksek olduğu soncuna ulaşılmıştır. B1 numunesinin sertlik değerinin B2 numunesinden daha yüksek olduğu tespit edilmiştir. B1 numunesinin düşük 1s1 girdisiyle birleştirilmesi nedeniyle elde edilen ince taneli mikroyapı, bu numunenin sertliğinin daha yüksek çıkmasına ana sebep olarak görülmektedir. 


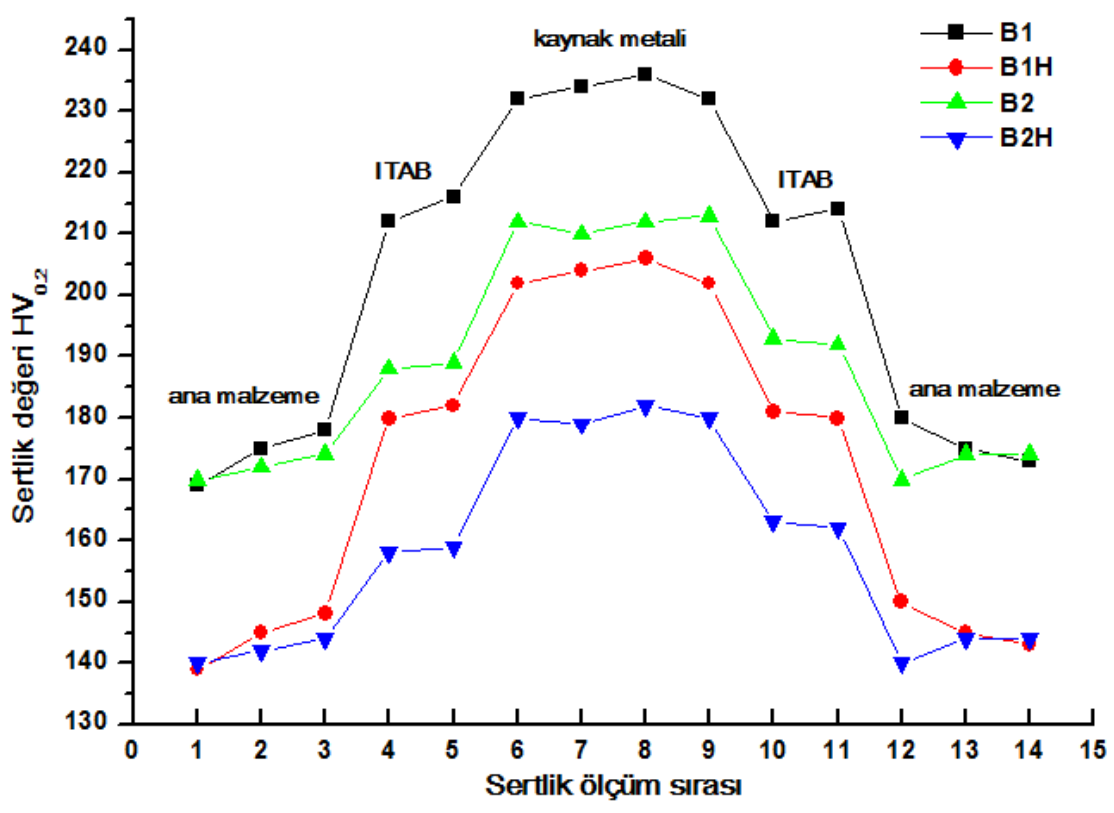

Şekil 11. Plazma kaynaklı birleştirmelerin sertlik dağıllımları.

Isıl işlem uygulanan $\mathrm{B} 1 \mathrm{H}$ ve $\mathrm{B} 2 \mathrm{H}$ numunelerinin kaynak metali ve ITAB sertliklerinin ana metalden daha yüksek olduğu tespit edilmiştir. B1H numunesinin sertlik değerinin yüksek 1sı girdisiyle birleştirilen B2H numunesinden yüksek olduğu belirlenmiştir. Isıl uygulanmamış ve 1 sıl işlem uygulanmış numunelerin sertlik dağılımları karşılaştırıldığında ise, ısıl işlem sebebiyle ana metal, ITAB ve kaynak metalinde açık bir şekilde sertlik azalışı oluştuğu sonucuna varılmıştır. Isıl işlem nedeniyle, ITAB ve kaynak metalinde gözlenen küçük hacimli martenzit tanelerinin temperlenmesinin sertlik azalmasına neden olan esas sebeplerden biri olduğu düşünülmektedir.

\section{Sonuçlar}

1. B1 numunesinin mikroyapısının neredeyse tamamı ferrit taneleri ve tane sınıllarında küçük hacimli martenzitten meydana gelmiştir. B2 numunesinin ise daha iri taneli ve sütunsal bir morfolojiden meydana geldiği gözlenmiştir. EDS analizlerinden numunelerde önemli bir element kaybı oluşmadığı tespit edilmiştir. Optik mikroskop ve SEM görüntülerinde kaynak dikişinde herhangi bir boşluk, çatlak veya karbür gözlenmemiştir. XRD analizi sonucunda da zararlı ikincil faz oluşumlarına rastlanmamıştır.

2. B1 numunesinin çekme ve akma dayanımı, B2 numunesinden daha yüksek bulunmuştur. Bu sonucun alınmasının nedeni ise, küçük yapılı ferrit tanelerinin oluşumu ve küçük hacimli tane sınırı martenzitinin bulunmasıdır. Tüm birleştirmelerin süneklik değerleri ise ana malzemeden düşük bulunmuştur. Isıl işlem, tanelerin irileşmesine sebep olarak birleştirmelerin dayanımlarını negatif olarak etkilemiştir. Düşük 1Sı girdisi sertlik dağılımlarını yukarı yönde etkilemiş ve kaynak sonrası uygulanan ssıl işlemle sertlikte belirgin bir azalma olmuştur.

\section{Teşekkür}

Yazarlar, malzeme temini ve plazma kaynak prosesi desteklerinden dolayı SILVERLINE Firmasına teşekkür etmektedir.

\section{Kaynakça}

[1] Lippold J C and Kotecki DJ 2005 Welding Metallurgy and Weldability of Stainless Steels. New York: A John Wiley \& Sons.

[2] Taban, E., Deleu, E., Dhooge, A. ve Kaluç, E. (2009). Laser welding of modified 12\% Cr stainless steel: Strength, fatigue, toughness, microstructure and corrosion properties. Materials and Design, 30, 1193-1200.

[3] Taban, E., Dhooge, A. ve Kaluç, E. (2009). Plasma arc welding of modified 12\%Cr stainless steel. Materials and Manufacturing Processes, 24, 649-656.

[4] Köse, C. ve Topal, C. (2019). Effect of post weld heat treatment and heat input on the microstructure and mechanical properties of plasma arc welded AISI 410S ferritic stainless steel. Materials Research Express, 6, 066517.

[5] Amuda, M. O. H. ve Mridha, S. (2011). An overview of sensitization dynamics in ferritic stainless steel welds. International Corrosion Science, Article ID 305793, 1-9.

[6] Correa, E. O., Costa, S. C. ve Santos, J. N. (2008). Weldability of iron-based powder metal materials using pulsed plasma arc welding process. Journal of Materials Processing Technology, 198, 323-329. 
[7] Taban, E. (2008). Toughness and microstructural analysis of superduplex stainless steel joined by plasma arc welding. Journal of Materials Science, 43, 4309-4315.

[8] Tan, H., Wang, Z, Jiang, Y., Han, D., Hong, J., Chen, L., Jiang, L. ve Li, J. (2011) .Annealing temperature effect on the pitting corrosion resistance of plasma arc welded joints of duplex stainless steel UNS S32304 in $1.0 \mathrm{M} \mathrm{NaCl}$. Corrosion Science, 53, 2191-2200.

[9] Kökey, C., Sezgin, S., Çavuşoğlu, N., İrizalp, S.G. ve Saklakoğlu, İ.E. (2016). İnce paslanmaz çelik sacların fiber lazer ile kaynak edilebilirliğinin incelenmesi. Mühendis ve Makina, 57, 66-72.

[10] Aydın, K. ve Karaağaç, İ. (2019). Lazer kaynaklı HSLA sac malzemelerde geri esnemenin deneysel araştırılması. Avrupa Bilim ve Teknoloji Dergisi, 17, 29-37.

[11] Gupta, S. K., Raja, A. R., Vahista, M. ve Yusufzai, M. Z. K. (2019). Hysteresis loop analysis of gas metal arc welded ferritic stainless steel plate. Materials Research Express, 6, 096110.

[12] Abioye, T. E., Omotehinse, I. S., Oladele, I. O., Olugbade, T. O. ve Ogedengbe, T. I. (2020). Effects of post-weld heat treatments on the microstructure, mechanical and corrosion properties of gas metal arc welded 304 stainless steel. World Journal of Engineering, 17, 87-96.

[13] Köse, C. ve Topal, C. (2019). Laser welding of AISI 410S ferritic stainless steel. Materials Research Express, 6, $0865 \mathrm{~g} 4$.

[14] Gordon, W. ve van Bennekom, A. (1996). Review of stabilisation of ferritic stainless steels. Materials Science and Technology, $12,126-131$.

[15] El-Batahgy, A. (1997). Effect of laser welding parameters on fusion zone shape and solidification structure of austenitic stainless steels. Materials Letters, 32, 155-163.

[16] Kou, S. (2003). Welding Metallurgy. Hoboken: Second Editon A John Wiley \& Sons INC. Publication.

[17] Amuda, M. O. H. ve Mridha, S. (2013). Grain refinement and hardness distribution in cryogenically cooled ferritic stainless steel welds. Materials and Design, 47, 365-371.

[18] Kah, D. H. ve Dickinson, D. W. (1981). Weldability of ferritic stainless steels. Welding Journal, August, 135-142.

[19] Pekkarinen, J. ve Kujanp, V. (2010). The effects of laser welding parameters on the microstructure of ferritic and duplex stainless steels welds. Physics Procedia, 5, 517-523. 